\title{
"DROIT DE SUITE" OU DIREITO DE SEQÜÊNCIA DAS OBRAS INTELECTUAIS
}

\author{
Fábio Maria De-Mattia \\ Professor Titular do Departamento de Direito Civil da \\ Faculdade de Direito da Universidade de São Paulo
}

\begin{abstract}
Resumo:
O autor aborda o conceito do "Droit de Suite", sua natureza jurídica, quais são os seus beneficiários, o período de duração, além da gestão, da cobrança e da necessidade das sociedades de titulares.
\end{abstract}

\begin{abstract}
:
The author board the conception of "Droit de Suite": your juridical nature, who are his beneficiaries, and the duration of the periodical, over and above the administration, the collection and the necessity of titleholders.
\end{abstract}

Unitermos: direito de seqüência; obras intelectuais; lei de direito autoral.

Sumário:

1. Importância do tema.

2. Conceito.

3. Natureza jurídica.

4. Abrangência, objeto ou obras sujeitas ao "Droit de Suite"

5. Beneficiários.

6. Duração.

7. Porcentagem.

8. A gestão, a cobrança, a necessidade das sociedades de titulares.

1. Importância do Tema.

O direito de seqüência sobre as obras intelectuais é um tema de alta relevância porque não é justo que o autor ou seus herdeiros fiquem compulsoriamente alheios, quando da transferência de uma obra de arte, de um manuscrito, de direito sobre obra intelectual, objeto de anterior cessão. 
Conforme informação de Ricardo Antequera Parilli o instituto foi adotado em trinta a quarenta países.

Os autores vendem as obras de arte, por exemplo, por um preço baixo e não é justo, equânime de que da valorização econômica da obra, do bem apenas os proprietários venham a se beneficiar.

É justo que após a transferência do direito necessário se mantenha ainda um vínculo entre o autor e a sua obra, porque este vínculo será o único remanescente de direito pecuniário a favorecer o autor ou seus herdeiros, sucessores, legatários ou instituições que sejam investidas de tal direito.

Javier Gutierrez Vincén explica:

"Com isso, estas criações de intelecto humano promovem um valor tal que tem dado a um fenômeno conhecido como plus-valia, que, pelas vendas sucessivas, transformaram a obra em objeto de especulações." ("La gestión de los derechos de autor en las obras plasticas" em Anais do "I Congreso Iberoamericano de Propriedad Intelectual" tomo I, pp. 249 e 250).

Para mim o que se quer é dar ao autor o direito de participação nessa valorização, pois, as obras intelectuais nada mais são do que a emanação da própria personalidade do seu criador. ("Estudos de Direito de Autor" São Paulo, Saraiva, 1975 , p. 91).

Éfren Paulo Porfírio de Sá Lima aponta que a:

"principal característica do direito de seqüência, para os países integrantes da Convenção de Berna, é a sua flexibilidade. Assim como a duração, os titulares $e$ as obras que são protegidas, variam de textura de país para país, a porcentagem incidente também não é a mesma nas legislações que o adotam. ("Droit de Suite", São Paulo, novembro de 1994, p. 40).

A importância do instituto se revela por ter Hubert Roger-Vasselin apresentado tese na Universidade de Paris II, em 1975, sob o título: "Le Droit de Suite après la mort de l'artiste", com 404 páginas. 
Anteriormente J. L. Duchemin, em 1948, escreveu obra sob o título "Le droit de suite des artistes". com 322 páginas, publicado em Paris, por Thuillies, Recueil Sirey, Editions Ramgal.

Há trabalhos de Wilhelm Nordemann, Wladimir Duchemin, Robert Rie, Paul Katzenberger.

2. Conceito.

Para Carlos Alberto Bittar é:

"um reflexo patrimonial do direito autoral reconhecido ao criador de obra intelectual, que o vincula perenemente, sob essa participação, à circulação da obra no mercado de arte. ("Direito de Autor" Rio de Janeiro, Forense Universitário, 1991, p. 54).

Continua o autor:

"Outrossim, na alienação de obra de arte ou de manuscrito, sendo originais, ou de direitos patrimoniais sobre obra intelectual, o autor tem direito, irrenunciável e inalienável, de participar na mais-valia que, em favor do vendedor, a eles advierem, em cada nova alienação (art. 39), ressalvada a resultante de simples desvalorização da moeda, ou a limitação do preço a valor inferior a cinco vezes o mínimo previsto ( ( $2^{\circ}$ )." (obra citada, p. 53).

3. Natureza jurídica.

Carlos Alberto Bittar, com propriedade, considera-o:

"direito de textura híbrida porque, tratado, entre nós, como direito pecuniário, possui duas características próprias do direito moral: a 
inalienabilidade e a irrenunciabilidade." ("Direito de Autor", obra citada, p. 54).

Sustento que:

"o direito de seqüência é um direito conexo ao direito de autor, conexo no sentido de ligado, dependente a ele porque da mesma natureza jurídica." (obra citada, p. 97).

Éfren Paulo Porfírio de Sá Lima se posiciona:

"o melhor argumento para definir o perfil jurídico da fattispecie em apreço é o mesmo utilizado para defender a natureza jurídica do direito de autor, isto é, como um direito sui generis." (obra citada, p. 36)

Adoto a posição de direito de autor sui generis, direito de textura híbrida. Esta última classificação "porque, tratado, entre nós como direito pecuniário, possui, conforme foi dito linhas acima, caracteres próprios do direito moral: a inalienabilidade e a irrenunciabilidade" como ensina Carlos Alberto Bittar (obra citada, p. 54).

José de Oliveira Ascensão enquadra-o como direito patrimonial:

"autoriza o autor a sacar um provento, não sem defendê-lo em aspectos pessoais. ("Direito de Autor e Direitos Conexos" Coimbra, Coimbra Editora, Limitada, 1992, p. 349).

A Lei portuguesa o cuida no art. 54 no capítulo da transmissão e oneração do conteúdo patrimonial do direito de autor.

Porfírio de Sá Lima seguindo a posição de Carlos Alberto Bittar:

"é fácil concluir que assim como o direito de autor é integrado por prerrogativas de ordem moral $e$ patrimonial, o droit de suite também o é." (p. 36)

A Convenção de Berna, art. 14 prevê o instituto. 
O caráter de direito moral de autor consiste no fato de a Lei n. 5.988, no art. 39, determinar a inalienabilidade e irrenunciabilidade de tal direito com o escopo de permitir tão-somente ao autor e seus sucessores o seu exercício.

É fácil compreender que o adquirente de uma obra de arte plástica, de um manuscrito ou de um determinado direito de autor que permite sua reprodução, representação ou execução se inexistisse a proibição legal só negociaria com a renúncia de tal direito ou com a transferência do mesmo. Ex.: editor cessionário de direito de autor sobre obra literária, obra musical, peça teatral; adquirente de obra plástica, direito sobre negativo de fotografia, projeto arquitetônico, etc.

4. Objeto ou abrangência ou obras sujeitas ao droit de suite.

Porfírio de Sá Lima aponta a existência de dois sistemas segundo a lição do autorizado Ricardo Antequera Parilli:

$\left.1^{\circ}\right)$ com alcance amplo;

$\left.2^{\circ}\right)$ com alcance restrito.

Como exemplos do sistema restritivo temos as "orientações traçadas" pela Convenção de Berna, Alemanha, Bélgica e França.

A Convenção de Berna insere no âmbito do direito de sequiência: somente as obras de arte originais e os manuscritos originais de escritores e compositores. Na versão da Revisão de Paris, a 24 de julho de 1971:

$\mathrm{O}$ art. 14 ter dispõe:

"1. Pelo que respeita às obras de arte originais $e$ aos manuscritos originais de escritores e compositores, o autor - ou, após a sua morte, as pessoas ou instituições a que a legislação nacional der legitimidade para tal goza de um direito inalienável de se beneficiar das operações de venda de que a obra for objeto depois da primeira cessão praticada pelo autor.

2. A proteção prevista na alínea supra só é exigível em cada país da União se a legislação nacional do autor admitir essa proteção e na medida em que o 
permita a legislação do país em que essa proteção é reclamada.

3. As modalidades e as taxas de percep̧ão são determinadas por cada legislação nacional.

Sobre a Lei francesa, Henri Desbois ensina que as expressões obras gráficas e plásticas abrangem as obras literárias, musicais, pinturas, esculturas, trabalhos arquitetônicos e desenhos. Em seguida o autor abre debate sobre os manuscritos de trabalhos musicais ou literários, quando conclui que os manuscritos podem ser incluídos na categoria das obras gráficas ("Droit d'Auteur" n. 303, p. 394).

Éfren Paulo Porfírio de Sá Lima que indica o "sistema de amplo alcance, como o nosso" aponta que diversas obras são tuteladas pelo direito de seqüência.

A Lei n. 5.988 no art. 39 dispõe:

"O autor, que aliena obra de arte ou manuscrito, sendo originais ou direitos patrimoniais sobre obra intelectual, tem direito irrenunciável e inalienável a participar na mais-valia que a eles advierem, em benefício do vendedor, quando novamente alienados.

O CNDA Conselho Nacional de Direito Autoral nos limites de sua competência procurou regulamentar o conteúdo do art. 39 que era letra morta na novel lei.

Para tanto, o presidente José Carlos Costa Netto, tendo presente processo gerado por consulta formulada por pessoa que se dizia beneficiária quanto ao Droit de Suite, deixado pelo artista Emiliano Di Cavalcanti, decidiu constituir comissão para estudar a regulamentação do referido art. 39 .

A comissão foi constituída por mim, como conselheiro presidente, e pelos conselheiros Henri Mario Francis Jensen e Cláudio de Souza Amaral.

Esta comissão apresentou projetos de Resolução que geraram as Resoluções ns. 22 de 9 de janeiro de 1981 e 27 de 9 de dezembro de 1981.

A primeira (Resolução CNDA n. 22) sob a denominação "Regulamenta o exercício do direito de seqüência" previsto no art. 39 e parágrafos, da Lei n. 5.988, de 14 de dezembro de 1973 e a segunda (Resolução CNDA n. 27) 
sob o título "Complementa as disposições da Resolução CNDA n. 22, de 9 de jareiro de 1981, sobre direito de seqüencia" indicam o conteúdo do que é o direito de seqüência, sẹndo a de número 27 datada de 9 de dezembro de 1981.

A Resolução n. 22 alcança obras de arte, manuscrito e os direitos patrimoniais sobre obra intelectual.

Diante da falta de possibilidade de aplicar diretamente o art. 39, o CNDA, através de Resoluções, procurou apontar o conteúdo do instituto.

$\mathrm{O}$ art. $1^{\circ}$ da Resolução CNDA n. 22 de 8 de janeiro de 1981 dispõe:

"O autor que alienar obra de arte ou manuscrito, sendo originais, ou direitos patrimoniais sobre obra intelectual, tem direito a participar da mais valia que a elas advierem, em benefício do vendedor, quando novamente alienados.

O parágrafo único dispõe:

"Para os efeitos da presente Resolução entende-se por:

1) "Obras de arte" as criações exteriorizadas sob a forma de:

a. pintura, desenho, escultura, gravura, litogravura, xilografia, pirogravura ou qualquer outro processo;

b. tapeçaria quando assinada e executada com base em desenho original;

c. plantas, esboços e maquetes arquitetônicos;

d. as manifestações de arte aplicada e quaisquer outras expressões artísticas protegidas no campo das artes plásticas.

2) "Manuscrito" o original, do próprio punho, ou datilografado, com emendas manuscritas do autor, ou ainda as provas impressas do livro com corrigendas por ele feitas a mão."

A Resolução n. 27, de 9 de dezembro de 1981, dispôs sobre as reproduções feitas e assinadas pelo autor: 
"Nos termos do art. $9^{\circ}$ da Lei n. 5.988/73, às reproduções feitas e assinadas pelo autor é assegurada a mesma proteção do original."

"§ $1^{\circ}$ - No caso das expressões de arte multiplicável, os efeitos desta Resolução aplicar-se-ão apenas sobre as cópias assinadas, numeradas ou codificadas $e$ autenticadas pelo autor ou seus herdeiros."

Lamentavelmente, o funcionamento do Droit de Suite foi impossibilitado, através da revogação das Resoluções ns. 22 e 27, e através da Resolução n. 49, de 25 de fevereiro de 1987, publicada no Diário Oficial da União, Seção I, p. 3.178, caracterizando retrocesso em matéria que tem recebido, ultimamente, interesse internacional na consolidação do instituto.

A Lei de Direito Autoral no art. 39 "caput" inclui na incidência do dispositivo os direitos patrimoniais sobre obra intelectual.

Quanto aos manuscritos além deles propriamente ditos, o corpus mechanicum datilografado, com pequenas anotações, é uma obra protegida." (De minha autoria, obra citada, p. 101).

E se perguntou: se o criador da obra intelectual, sabendo da possibilidade de conseguir recursos através da feitura de vários originais, executar vários exemplares, seriam obras protegidas? Os autores têm entendido que sim.

Então, se os autores fazem dois, três ou quatro originais, entregam um para o editor e ficam com os outros dois ou três, a família após sucessivas vendas desses originais poderá ter direito a uma plus valia.

Porfírio de Sá Lima demonstra que o Droit de Suite:

"não deve incidir somente quando a obra for objeto de venda e compra, mas em todas as alienações onde houver valorização da obra."

Um problema prático que se propõe é o se o direito de seqüência deveria incidir tão-somente nas vendas em leilões ou por marchands. 
José de Oliveira Ascensão aponta tal situação para as obras de arte e assevera:

"Nomeadamente, em relação, às obras de arte restringem freqüentemente às alienações em que intervém comerciante ou leiloeiro." (p. 322).

Para este autor:

"Portanto, é só ao titular originário que cabe beneficiar do direito de seqüencia."

O professor Antonio Chaves informa que diferentemente da lei brasileira e da Convenção de Berna, a lei espanhola no art. 24 (Lei n. 22 de 11 de novembro de 1987), seguindo o exemplo dos textos equatoriano, chileno e peruano, não alude aos manuscritos dos escritores e compositores.

O direito de seqüência não alcança as artes aplicadas.

O Droit de Suite não alcança as obras arquitetônicas na observação de Ricardo Antequera Parilli.

Wlademir Duchemin em trabalho intitulado "Suggestions en vue d'une amélioration de la protection des photographies dans la Communauté Européenne", em RIDA, v. 105, na p. 11 afirma:

"Mas em todos países que o instituíram (França, Bélgica, Itália, Alemanha Federal e Luxemburgo), excluíram a fotografia do campo de aplicação do direito de seqüencia."

Porfírio de Sá Lima demonstra que o Droit de Suite:

"não deve incidir somente quando a obra for objeto de venda e compra, mas em todas as alienações onde houver valorização da obra." ("Droit de Suite", São Paulo, novembro de 1994, trabalho apresentado no curso de pós-graduação da Faculdade de Direito da Universidade de São Paulo). 
5. Beneficiários.

Porfírio de Sá Lima aponta existirem três sistemas (obra citada, p. 39):

a. Beneficia somente os autores (o adotado na Espanha - art. 24, da Lei n. 22, de 11 de novembro de 1987) (quando cita Javier Gutierrez Vincén, p. 253).

b. São titulares os autores e seus sucessores - art. 39 combinado com o art. 42 e seus $\S \S$ da Lei n. 5.988/73 (Fábio Maria De-Mattia, obra citada, p. 99). Com relação aos beneficiários o instituto objetiva, primeiramente, garantir uma situação econômica para o autor da obra intelectual. No caso de sua inexistência, falta, deverá beneficiar os seus herdeiros ou legatários; ou seus sucessores.

c. São beneficiários os autores, seus sucessores e, caso o autor não tenha sucessores, a titularidade do direito de participação é transmitida para uma instituição.

A transferência da titularidade do direito de seqüência a uma instituição está prevista pela Convenção de Berna (art. 14 ter).

Porfírio de Sá Lima, na nota 28 de seu trabalho, refere-se a Paolo Greco e Paolo Vercellone art. 150 da Lei italiana, ao determinar que, em nãoinstituído sucessor, ou, caso já se tenha passado o período previsto em seu benefício, o Droit de Suite passará a beneficiar o Ente Nazionale per l'assistenza per i pittori e gli scultori órgão que cuida da assistência e da previdência dos autores, pintores, cenógrafos, etc.

6. Duração.

Porfírio de Sá Lima examina de maneira irretocável o tema da duração do Droit de Suite na p. 40 de seu excelente estudo.

A duração do direito de participação varia de país para país.

Entretanto, seguindo-se a orientação unionista, o direito. de seqüela deverá durar por toda a vida do autor e pelo lapso de tempo pos mortem que a legislação de cada país fixar.

Entre nós, perdura durante toda a vida do autor (art. 42, caput); os filhos, os pais, ou o cônjuge gozarão vitaliciamente do direito de seqüência se lhes forem transmitidos por sucessão mortis causa (art. $42, \mathbb{}\left(1^{\circ}\right.$ ); e os demais sucessores 
gozarão deste direito por um período de sessenta anos, a contar do primeiro dia de janeiro do ano subseqüente ao do falecimento do autor, ( $\$ 2^{\circ}$ do art. 42$)$.

\section{Porcentagem.}

Porfírio de Sá Lima aponta que as legislações podem ser divididas, quanto ao percentual de incidência, em duas largas classes.

A primeira, quanto a exigência de mais-valia da obra.

A segunda, quanto à variação da porcentagem.

Ou seja, optou-se por uma porcentagem sobre o valor da alienação, quanto ao nosso sistema (obra citada, p. 41).

Alguns sistemas prevêem a incidência do Droit de Suite sobre todas as vendas, independentemente do problema da plus-valia. Outros sistemas entendem que a incidência só deva se dar no caso de incidência da plus valia (nosso estudo já citado, p. 104).

Porfírio de Sá Lima aponta quanto à exigência da mais-valia ou-não, existem dois grupos de legislações:

$1^{\circ}$ ) em que as porcentagens que correspondem ao autor só serão aplicadas se houver mais-valia (exemplo: o da Lei brasileira art. 39 da Lei n. $5.588 / 73)$.

A respeito do art. 39 da nossa Lei de Direito de Autor ressalte-se que estipula $20 \%$ (vinte por cento) sobre o aumento do preço que deverá beneficiar o autor ou seus herdeiros. Esta porcentagem está fixada de maneira realista.

$2^{\circ}$ ) que, para a incidência do porcentual em benefício do autor (ou a quem a lei der legitimidade para tal), não há necessidade de ocorrer a plus-valia (verbi gratia: o sistema franco-belga). (Éfren Paulo Porfírio de Sá Lima, obra citada, p. 41).

Quanto a este segundo grupo, as mcdalidades podem ser:

a. o percentual de incidência é fixo (exemplo: o sistema alemão prevê uma porcentagem fixa de $5 \%$ sobre o valor total da transferência da obra.

b. a porcentagem incidente é variável (exemplo: o da Lei belga cujo percentual varia de 2 a $6 \%$, dependendo do valor da venda).

O mesmo quanto ao sistema italiano: $2 \%, 3 \%, 4 \%, 5 \%, 6 \%, 7 \%, 8 \%$, $9 \%$ e $10 \%$ 
Porfírio de Sá Lima entende ser essa uma boa solução para os casos em que a obra seja alienada a título gratuito, depois da primeira cessão praticada pelo autor.

O importante é frisar que para evitar que muitos Estados deixassem de subscrever a Convenção de Berna nas suas sucessivas revisões, entendeu-se que a Convenção não deveria ter interferência alguma na fixação da porcentagem. Isto caberá à legislação nacional que a seu bel-prazer fixará aquilo que bem entender. Veja-se o art. 14 ter, n. 3:

"As modalidades e as taxas de percepção são determinadas por cada legislação nacional."

8. A Gestão, a Cobrança, a Necessidade das Sociedades de Titulares.

Na França há duas sociedades organizadas para tal fim, na Alemanha e Bélgica apenas uma.

No Brasil o mesmo não ocorre; sem o que o instituto nunca funcionará. $\mathrm{O}$ estatuto da sociedade francesa pode ser aproveitado para tal fim.

Por ocasião das Resoluções ns. 22 e 27 entreguei a artistas do Rio e São Paulo a ABAP Associação Brasileira de Artistas Plásticos cópia de referido estatuto.

É fundamental criar uma sociedade dos titulares de direitos e no caso de marchands e leiloeiros ficariam responsáveis para depositar o montante devido junto à sociedade.

Tem-se comprovado que diante da dificuldade em efetuar a cobrança algumas legislações estão circunscrevendo o instituto às alienações em leilões e através de marchands.

São Paulo, de janeiro de 1997. 